\title{
Contour Tones as Phonemic Primes in Grebo
}

\section{Paul Newman}

\section{Department of Linguistics, Indiana University}

\section{Introduction *}

The normal (and usually correct) practice in African linguistics is to treat contour tones as sequences of level tones. In Hausa, for example, where Falling tone is easily analyzed as High plus Low on a single syllable, verbs with the surface tone pattern F H belong to the same class as $\mathrm{H} \mathrm{L} \mathrm{H}$ verbs, CVC words with F tone occur as contracted forms of CVCV words with $H$ L tone, etc. In Grebo, on the other hand, the standard treatment of contours does not hold. Rather, a careful study of the language leads to an analysis that recognizes two contour tones as primes along with the level tones. In this paper, I present a sketch of Grebo tonal phenomena and provide justification for the analysis of the contours as tonemic units.

Grebo is a $\mathrm{Kru}$ language spoken by some 80,000 people in southeastern Iiberia (Innes 1981). It belongs to the western branch of the Kru family along with Bassa, Klao (= "Kru"), wobe, and other closely related languages of southern Liberia and Ivory Coast (Lafage 1978, Marchese 1979).

For Grebo we are fortunate in having the excellent grammar and dictionary of Innes (1966, 1967), works on which I have relied heavily. ${ }^{1}$ My own research on the language has been carried out in the United States with a single speaker, Mr. Mlen Too Wesley, who comes originally from Cape Palmas in the "Seaside Grebo" area. Since I have never been to Grebo country, I am unable to say whether the discrepancies noted between my findings and those of Innes are due to idiosyncracies on the part of my assistant or of his or whether they represent true dialect differences. Although my interpretation of the Grebo tonemic system differs significantly from that of Innes, our tonal transcriptions match very closely; thus there is independent confirmation of the tonal facts at the "observational level". Whenever it is necessary to specify the source of my data, I shall indicate [GI] for Innes' published materials and [MTW] for my notes and tapes taken directly from Mlen Too Wesley. 


\section{Non-tonal phonology}

Before turning to tone, let me briefly outline the non-tonal phonology of Grebo. Since the reader is either familiar with Innes' works or will necessarily turn to them for further study, I shall present the segmental inventory as done by him accompanied by comments based on my own research.

a. Consonants. Grebo has the following consonant phonemes: P, b, t, d, k, g, kp, gb, ky, gy, hm, m, hn, n, ny, n, nm, hl, l, f, s, h, hw, w, (nw), y. Comments: (i) The putative phoneme / $\mathrm{ww} /$, which is pronounced as $[\widetilde{w}], i . e$. as a nasalized semivowel without full velar closure, should be treated as an allophone of $/ \mathrm{w} /$ in the environment of a following nasal vowel. (Innes himself switches to this interpretation in a later paper (1981).) This analysis of $[\tilde{w}]$ seems correct even if one eschews the possible parallel treatment of the simple nasal consonants as nasalized stops, i.e. the interpretation of [na] as /dã/, etc. ${ }^{2}$ (ii) Innes describes hm, hn, $h l$, and hw as the voiceless correlates of $\mathrm{m}, \mathrm{n}, \mathrm{l}$, and $w$ respectively. In MTW's speech, hm and hn sound like voiced nasals with slight preaspiration. Viewed comparatively, Innes' use of digraphs for what he considers to be unitary voiceless nasals is fortuitous since historically the sounds derive from clusters, e.g. hne 'fish' < *zne cf. Wobe smi, Bassa zimii. In MTW's speech, the phoneme /hl/ is not voiceless nor does it have any preaspiration. Its distinctive characteristic is its apical articulation as opposed to the laminal articulation of the phoneme /l/. Historically /hl/ derives from sl or $z$ l clusters while /l/ derives from $d l$ or $j /$ clusters. The phoneme /hw/ is the voiceless counterpart of /w/. MTW makes no contrast between /w/ and / hw/ when a nasal vowel follows, i.e. nwa and hwã in Innes' transcription are both [w̃ã]/wã/. (iii) MTW pronounces the palatal "plosives" ky and gy as affricates; I transcribe them as $c$ and $j$ accordingly.

b. Vowels. Grebo has the following vowel phonemes: $1, e,(\dot{e}), \varepsilon, a, j,(\dot{0})$, $\circ, u, \tilde{I},(\widetilde{e}), \tilde{\varepsilon}, \tilde{a}, \tilde{s},(\widetilde{o}), \tilde{u}$. Comments: (i) MTW seems to have lost the contrast widespread in Kru between the dotted vowels (termed "muffled" by Innes following Sapir (1931)) and the corresponding clear vowels. The o/o contrast is apparently gone altogether whereas the $e / \dot{e}$ contrast is marginally preserved only in the most careful speech. Comparing MTW with GI, one finds that $* / \& /$ and */o/ have something shifted to $/ \varepsilon /$ and $/ \supset /$ and sometimes to /e/ and /o/ under conditions that are not clear. The "muffled" vowels are not transcribed in this paper. (ii) Innes describes all seven non-muffled 
vowels as having nasal correlates. In MTW's speech, / $/$ / and / $/$ / have a questionable status. In many cases */ẽ/ has been replaced lexically by /ĩ/ or $/ \tilde{\varepsilon} /$. Even where / $/ \tilde{f}$ has to be posited synchronically, it tends towards $[\tilde{\varepsilon}]$ in rapid speech. Similarly, /ö/ is generally pronounced as $[\tilde{u}]$ or, more often, as [J], thereby merging with those phonemes. Since vowels after nasal consonants are automatically nasal, I shall follow Innes' practice of leaving them unmarked. Note that this is strictly a transcription convention and not meant as an indication of how nasalization in Grebo should be treated analytically.

(c) Clusters. Innes claims that the Cl clusters that occur in ClV... words can all be regarded as syncopated forms of CVCV words, where $c_{2}$ is /d/ or $/ \mathrm{n} /$. Comments: (i) Whatever the historical correctness of this analysis-and one would have to go far beyond Grebo into proto-western-Kru before it really would hold--it cannot be accepted synchronically. Some words in Grebo do have $\mathrm{ClV}$ and $\mathrm{CVCV}$ alternants, but there are many words, including basic words, where only $\mathrm{ClV}$ forms occur, e.g. pl $\tilde{\varepsilon}$ 'rat', ml $\tilde{\varepsilon}$ 'meat', bla 'rice', kla 'bone'. (ii) Innes' phonetic description of the $\mathrm{Cl}$ clusters (however one analyzes them) also needs rectification. Innes asserts that a transcription such as blo 'frog' gives an accurate representation of the pronunciation of that and similar words. In MTW's speech, which in this instance is almost certainly typical of the language, the cluster /1/ when followed by a rounded vowel is generally pronounced as an $r-1 i k e$ tap rather than as a lateral [1],

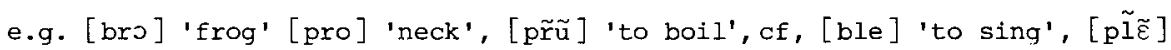
'rat', [kla] 'bone', [mĩr] 'to bite'. (iii) While on subphonemic matters, one should add that at normal speech tempos, intervocalic/d/ in true CVCV words is also pronounced [l] or $[r]$, in this case normally [r], e.g. [kuri] /kudi/ 'belly', [yiri]/yidi/ 'to steal', [kore] /kode/ 'to cough', [dalo] /dado/ 'cloth'. The failure to mention this is a curious omission by Innes since this pronunciation is a pervasive feature of Grebo and one that we know was already prevalent in the mid-nineteenth century (see Koelle 1854). Less common, but also quite noticeable, is the pronunciation of intervocalic $/ n /$ as $[\tilde{r}]$. This is always accompanied by severe reduction of the preceding vowel such that one could argue that the words had really become CCV in shape,

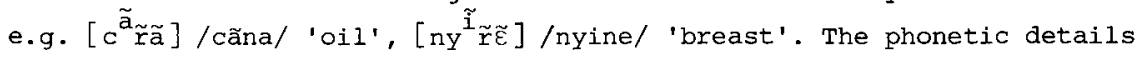
discussed above will not be represented in the transcription employed in this paper, i.e. the cluster $/ 1 /$ will be written as $/ 1 /$, whether pronounced as $[1]$ or $[r]$, and the intervocalic alveolars will be transcribed as $/ a /$ or $/ \mathrm{n} /$. 
(d) Stress. Innes describes Grebo as havina two distinctive degrees of stress. Comment: In my work with MTW, I was unable to identify and verify the stress phenomena described in interesting detail by Innes.

\section{The tonal system}

Grebo is generally described as a language with four discrete tone levels. The contrast on monovocalic words, i.e. monosyllabic words with a simple short vowel, is shown in (1) and (2). Tone is indicated by numerals, with 1 representing the highest and 4 the lowest.

\begin{tabular}{|c|c|c|}
\hline & 1 & 'store' \\
\hline & 2 & 'tree, stick \\
\hline $\mathrm{mz}$ & 3 & 'you (sg.)' \\
\hline & 4 & 'herring' \\
\hline
\end{tabular}

$$
\begin{aligned}
& \text { do gla bla } 1444 \text { 'Doe distributed rice'3 } \\
& \text { - gla bla } 244 \text { 'he distributed rice' } \\
& \text { a gla bla } 3444 \text { 'we distributed rice' }
\end{aligned}
$$

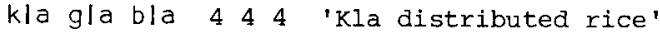

Grebo also has contour tones on short vowels, the most common (the only?) being a high rise 21 and a lower rise 32 , e.g.

$$
\begin{array}{lll}
\text { lu } & 21 & \text { 'head' } \\
\text { na } & 21 & \text { 'to drink' } \\
\text { ga } & 32 \text { 'thigh' } \\
\text { to } & 32 \text { 'to buy' }
\end{array}
$$

It is not clear whether Innes considers the contours to be combinations of level tones or distinct tonemes in their own right. He never directly addresses the issue. However, by his manner of representing the tones by numerals, by his highlighting the four-way contrast, and by his treatment of tonal sequences in longer utterances, he implies that the four level tones constitute the tonemic primes. This seemingly straightforward analysis presents a number of anomalies. Monovocalic verbs, for example, fall into four tone classes (Innes 1966:60): $A=21, B=2, C=32, D=4 .{ }^{4}$ While tonal gaps in lexical classes are not in themselves surprising, it is strange not to find verbs with the supposedly basic high tone. Moreover, given the absence of the simple tones 1 and 3 in monovocalic verbs, it is hard to explain why they should show up 
in the 21 and 32 contours. When one turns to nouns, the same situation reappears. According to Luckau $(1975: 42), 5$ the most common tones found in monosyllabic non-loanwords are (in decreasing frequency) $21,2,4$, and 32 . Tone 1 occurs readily in loanwords but uncommonly in native words. Tone 3 in monovocalic nouns is rare. The distributional situation, with examples, is depicted in (4).

a. Verbs

b. Nouns

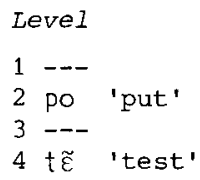

Leve 1

1 (loanwords)

2 na 'fire'

3 (rare)

4 fã 'herring'
Contour

21 la 'kill'
---
32 to 'buy'
---

Contour

$21 \mathrm{ni}$ 'water'

32 gbe 'dog'

As soon as one organizes the facts on paper as in (4) it becomes clear that the distributional "anomalies" are not properties of the language but rather are artifacts of the tonal analysis adopted. To rectify the situation all one has to do is to collapse the level and contour tone columns into a single column, with the contours treated as tonemic units rather than as sequences. One then arrives at the four basic tones of the language: $R$ (High Rise) [-low, +rise], numerically 21; M (Mid) [-low, -rise], numerically 2 ; r (low rise) $[+$ low, trise $]$, numerically 32 ; and $L$ (Low) [+].ow, -rise], numerically 4 , e.g. 6

$\begin{array}{lllllll}\mathrm{R} & 21 & \text { la } & \text { 'kill' } & \mathrm{ni} & \text { 'water' } & {[\text {-low, +rise }]} \\ \mathrm{M} & 2 & \text { po } & \text { 'put' } & \text { na } & \text { 'fire' } & {[\text { low, -rise }]} \\ \mathrm{r} & 32 & \mathrm{t} \tilde{\mathrm{D}} & \text { 'buy' } & \text { gbe } & \text { 'dog' } & {[\text { low, +rise }]} \\ \mathrm{L} & 4 & \mathrm{t} \tilde{\tilde{\varepsilon}} & \text { 'test' } & \text { fã } & \text { 'herring' } & \text { [+low, -rise }]\end{array}$

To the extent that levels 1 and 3 represent separate tonemes, to be discussed below, they will be indicated $T$ (Top) and $\mathrm{m}$ (lower mid). 7

With the High Rise particularly there is other language internal evidence that argues against a sequential analysis. Unlike the other possessive pronouns, which are tonally invariant, the first person pronoun na has two tonal alternants. Before a noun with tone 1 , it is 2 , e.g. na to 21 'my store', na sui 21.1 'my shoes'. Before a noun with tone 2 or lower the pronoun has 
tone 1, e.g. na tu 12 'my stick', na be 12 'my feet'. Before divocalic 2.2 and 2.3 nouns it is also 1 , e.g. na nyeno 12.2 'my blood', na noa 12.2 'my ear', na dado 12.3 'my cloth'. If the $\mathrm{R}$ (21) tone were really a sequence of $2+1$, one would expect the pronoun to have tone 1 before 21 nouns. But this is not the case: before 21 nouns, na is 2 , e.g. na ta 221 'my salt', na lu 221 'my head'. Interestingly, before polysyllabic nouns with 2.1 tone, na is also 2, e.g. na habe 22.1 'my chicken', na wudi 22.1 'my money'. The explanation for this is that these words also manifest $R$ tone, where the domain of the contour toneme is the whole word rather than a single segment. Tonally, 'my salt' and 'my chicken' are both /M R/. Using basic tonemes for the nouns instead of numerals, the description of the allomorphs of the first person possessive pronoun becomes simple: na is 2 before $T$ or $R$ (tones structurally higher than $M)$; it is 1 elsewhere.

With tone $R$ (21), evidence at the phonetic level also supports the unitary over the decompositional analysis. In Grebo there is a downdrift phenomenon that lowers M (2) to 3 when preceded by L (4). The lowering does not affect tone 21 in the same manner, a difference that is consistent with the analysis of 21 as $\mathrm{R}$ rather than as $2+1$, e.g.

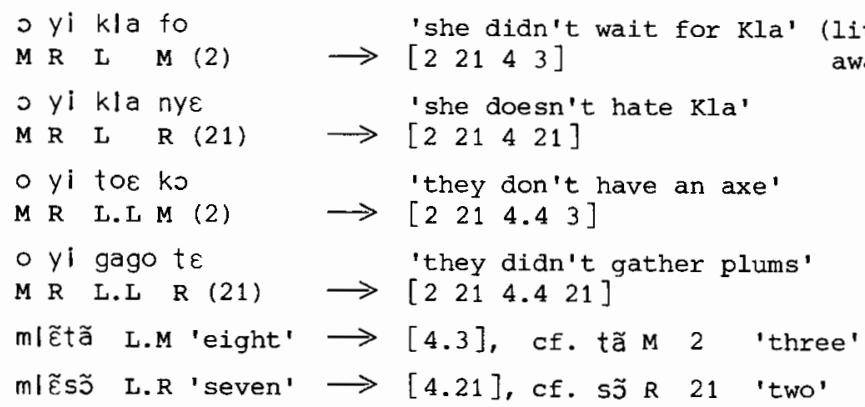

Given the interpretation of the 21 contour as a basic toneme that in some sense occupies the high tone slot, one needs to account for level tone 1 . This has a number of different sources. In polyvocalic 2.1 words, the 1 is a surface component of the $\mathrm{R}$ tone, e.g. wudi [2.1] 'money' has a single toneme $/ R /$. In other polyvocalic words, the level 1 is an allophone of $R, e . g$. munu [1.4] 'skate (fish)' is phonemically/R.L/, not */T.L/; baa [4.1] 'perhaps' is /L.R/, not */L.T/. With function words such as pronouns, conjunctions, locatives, etc., tone 1 represents a grammatically restricted, lexically specific variant of the basic $R$ tone. These words, which tend to be mono- 
syllabic with a single short vowel, e.g. mj 'me', ní 'and', ké 'at', dé 'there', can be thought of as half-moric words with the initial part of the glide lopped off. Synchronically they now probably have to be treated as having $T$ rather than $R$ tone. In the case of loanwords, tone 1 is the discrete Top tone (historically derived in many cases from a falling tone) which synchronically contrasts with the $\mathrm{R}\left(<*_{\mathrm{H}}\right)$ tone, e.g. to $\mathrm{T}(1)$ 'store', f/o $\mathrm{T}$ (1) 'bread', ki T (1) 'king'.

Like level tone 1, surface level tone 3 also has to be explained in a number of different ways. In polyvocalic 3.2 words, the 3 is the initial surface component of the unit $r$ toneme, e.g. woda [3.2] $=/ r /$ 'vomit'. In words with the tonal sequence 4.3 , the 3 is an allophone of M lowered by downdrift. (Innes specifically notes the absence of 4.2 words.) For example, hobo [4.3] $=/$ L.M/ 'moon', gbae $[4.3]=/$ L.M/ 'hoop'. In 2.3 and 32.3 sequences, the 3 is an allophone of $\mathrm{L}, \mathrm{e} . \mathrm{g}$. dado $[2.3]=/ \mathrm{M} . \mathrm{L} /$ 'cloth', beo $[2.3]=/ \mathrm{M} . \mathrm{L} /$

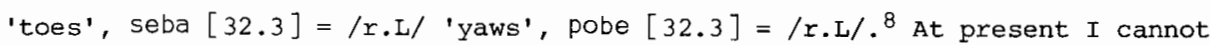
offer a satisfactory explanation for the 3.3 sequence that is quite common in nouns, e.g. gaba 3.3 'jaw', pea 3.3 'peppers'. One could treat 3.3 as $/ \mathrm{m} . \mathrm{m} /$, but then one would be left with exactly the same problem but only at the historical level. Alternatively one could interpret $3.3 \mathrm{as} / \mathrm{r} . \mathrm{r} /$, a nonoccurring sequence of two basic tones, but it is far from evident why two rises should be realized as level tones. Interestingly, MTW generally pronounced CVV words transcribed as 3.3 by Innes with a 3.2 rise, e.g. kõã 'work' GI 3.3 = MTW 3.2; saa 'soup' GI $3.3=$ MTW 3.2 .

Apart from the cases described above, surface 3 tones also appear commonly in Grebo as a result of grammatical processes and word formation rules. For example, in nominal compounds the second noun takes tone 3 (probably reflecting a raised $L$ tone) regardless of its underlying tone, 9 e.g. bliyu 2.3 'calf'

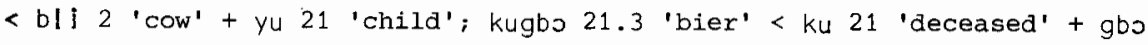
32 'platform'. Here one can also cite a number of derivational suffixes (originally probably the second member of compounds) which have inherent level tone 3, e.g. wudiye 21.3 'a unit of money'; wiye 32.3 'a single palmnut'; vaape(e) 4.1.3(3) 'a Vai person'; hõnape 3.2.3 'slackard' (< hõna 'be lazy').

\section{Historical/comparative perspective}

If the contour tones in Grebo were really sequences of independent level tones that had become phonetically compressed, one would expect to see evidence of 
the separate tones in related languages. Instead, when one compares Grebo with closely related western Kru languages one generally finds the contours corresponding to single unitary tones that can be reconstructed as unit

tonemes for proto-Western Kru.

The $R$ (21) tone in Grebo corresponds regularly to simple high tone in Bassa (Hobley 1964, n.d.) and in Wobe (Bearth and Link 1980, Hofer and Link 1980). It corresponds to what is transcribed as M.H (2.1) in Klao (Lightfoot 1974, Duitsman et al. 1975). Since Klao is like Grebo in that this contour is extremely common while tone 1 is rare, it is likely that, historically at least, the 21 contour in klao also constituted a basic unit tone and not a tone sequence. ${ }^{10}$ Note that disyllabic words in Grebo with 2.1 tone, which I have claimed are monotonal, have the same tonal correspondences as words with the surface 21 contour.

\begin{tabular}{|c|c|c|c|c|}
\hline Gloss & $\begin{array}{l}\text { Grebo } \\
R=21\end{array}$ & $\begin{array}{l}\text { Bassa }{ }^{11} \\
\mathrm{H}(\mathrm{H})\end{array}$ & $\begin{array}{l}\text { Wobe }{ }^{12} \\
\mathrm{H}\end{array}$ & $\begin{array}{l}\text { Klao } \\
?=21\end{array}$ \\
\hline bone & kla & kpa & $\mathrm{kpa}$ & $\mathrm{kpa}$ \\
\hline guts & $\mathrm{mi}$ & $m \varepsilon$ & $\mathrm{me}$ & -- \\
\hline hear & wธ̃ & $w \widetilde{5}$ & ws̃ & wร \\
\hline kill & la & daba & $d b a$ & dla \\
\hline learn & $c \tilde{e}$ & $c \tilde{\varepsilon}$ & cễ̃ & $c \tilde{\varepsilon}$ \\
\hline nose & me & mana & $\mathrm{mla}$ & mna \\
\hline salt & ta & t 2 & $t \tilde{s}$ & tõ \\
\hline see & $y i$ & dye & je & je \\
\hline money & wud $i$ & widi & we i & -- \\
\hline name & nyene & nyene & nyne & nyne \\
\hline oil & cãna & cana & cna & cna \\
\hline steal & yidi & dyidi & jri & $j \mid i$ \\
\hline
\end{tabular}

It seems clear that the High Rise ( $R$ ) one now finds in Grebo developed historically from a phonemic High level tone. The process would have been one of glide formation, comparable to the common process of diphthongization of vowels. ${ }^{13}$ The comparative evidence does not support the idea that the corresponding low rise $(r)$ developed in a comparable fashion from a level tone constituting a fourth distinct register. Rather, it suggests that $r$ goes back to a basic rising contour in the low to mid range reconstructable for proto-Western Kru. Grebo $r$ (32), the reflex of the earlier glide, corresponds to mid in Bassa, to a level low (or less often, a mid-low fall) in $\mathrm{Klao}$, and to a similar low rise in wobe. As in the case of $R$, the Grebo toneme $r$ has the same correspondences whether it is on a monovocalic word or whether it extends over two syllables. 
(8)

\begin{tabular}{|c|c|c|c|c|}
\hline Gloss & $\begin{array}{l}\text { Grebo } \\
r=32\end{array}$ & $\begin{array}{l}\text { Bassa } \\
\text { M(M) }\end{array}$ & $\begin{array}{l}\text { Wobe }{ }^{14} \\
r=43\end{array}$ & $\begin{array}{l}\mathrm{Klao} \\
\mathrm{L}\end{array}$ \\
\hline buy & $t \tilde{\jmath}$ & d̃ & $t \tilde{e}$ & $t i$ \\
\hline dog & gbe & gbe & gbe & gbe \\
\hline fight & hwõ & vวั & f & fร̃ \\
\hline fish & $h n \varepsilon$ & zimi i & $\mathrm{smi}$ & $n \varepsilon$ \\
\hline four & $h \tilde{\varepsilon}$ & hĩnye & $\Gamma \varepsilon$ & $p i \varepsilon$ \\
\hline leopard & $j i$ & ji & $\mathrm{ci}$ & -- \\
\hline repair & mlã & gma & -- & oma \\
\hline count & hed $\varepsilon$ & $z \varepsilon d \varepsilon$ & -- & $s \mid \varepsilon$ \\
\hline town & wodo & hwodo & -- & $\mathrm{klo}$ \\
\hline vomit & woda & hwada & kwla & wla \\
\hline
\end{tabular}

To sum up to this point, Grebo has four primary tonemes: two level tones $(L$ and $M$ ) and two contour tones ( $R$ and $r$ ). These tones derive historically from a system of three discrete levels (L, M, H) plus a basic low-mid rising contour. The level tones 1 (Top) and 3 (lower $\mathrm{mid}$ ) have a secondary status in Grebo, being the result of internal tone processes and recent historical developments.

4. Tone spreading and tonal alternations

Thus far we have been concerned with showing why the contours in Grebo should be considered as units rather than as sequences. A second question is whether these unit tonemes, so analyzed, need be specified as contours underlyingly or whether they could be treated phonemically as level tones with the phonetic glide provided by low level phonetic rules. This latter analysis is the one adopted by Hobley (1964) and Thalmann (1978, 1980) for closely related western Kru languages. It does not, however, seem correct for Grebo: in Grebo the two unit contours behave as contours in a manner that sets them apart from the level tones. The most pervasive characteristic of the contours as opposed to the level tones is their propensity to spread to the right and expand their domain. ${ }^{15}$ This can be seen in the numerous tonal alternations so well documented by Innes. I shall describe just a few of them.

4.1. The Tense Marker -da

The tense suffix -da $\left(\rightarrow\right.$ na/ $\widetilde{v} \_$, which Innes describes as the "before yesterday past", has inherent $M(2)$ tone, e.g. 

o dida d $\varepsilon$
- muna kao
22.22
$\begin{array}{lll}2 & 2.2 & 1.4\end{array}$
o hoda
- kodeda
○ $m ! \tilde{\varepsilon} n a$
o glada wud $\mathrm{i}$
23.2
2 2.3.2
$24.2\left(\rightarrow\left[\begin{array}{ll}2 & 4.3\end{array}\right]\right)$
24.22 .1

\author{
'he ate something' \\ 'they went home' \\ 'it was abundant' \\ 'they coughed' \\ 'he jumped' \\ 'they divided the money' 16
}

When attached to a verb with $R$ (21) tone, the suffix appears with tone 1 and the stem with tone 2 , i.e. the lexical contour on the verb spreads to the right and incorporates the tense suffix within its domain. The low rise ( $r$ ) operates in parallel fashion (although the operation can only be seen on the tone of the verb stem since the suffix would be 2 in any case), e.g.

\begin{tabular}{|c|c|c|}
\hline $\begin{array}{llll}0 & 1 a & d a & d \varepsilon \\
2 & 21 & 2 & 2\end{array}$ & $\begin{array}{lll}0 & \text { lada } & d \varepsilon \\
2 & 2.1 & 2 .\end{array}$ & $\begin{array}{l}\text { 'they killed something' } \\
\text { (< la } 21 \text { 'kill') }\end{array}$ \\
\hline nana $\mathrm{ni}$ & 22.121 & 'she drank water' (< na 21) \\
\hline sinina & 22.2 .1 & 'she sneezed' $(<\operatorname{sini} 21)$ \\
\hline yidida to $\varepsilon$ & 22.2 .14 .4 & 'he stole an axe' (<yidi 21) \\
\hline พั̃กล & 23.2 & 'they fought' $\quad(<w \widetilde{5} 32)$ \\
\hline$p \mid \varepsilon d a$ yu & 23.221 & 'she bathed the child' $(<p \mid \varepsilon \quad 32)$ \\
\hline hõnana & 23.3 .2 & 'they were lazy' (< hõna 32) \\
\hline ededa $d \varepsilon$ & 23.3 .22 & 'he counted something' (< hede 32$)$ \\
\hline
\end{tabular}

The first person singular subject pronoun has two alternative forms: /ni/ and $/ \%$ (a floating $T$ (1) tone). In MTW's speech, the expressed ni form does not normally affect the tone of the following verb. The floating tone, however, obligatorily grounds to the right and replaces the lexical verb tone, whatever it is. Like the other level tones, the $T$ tone now found on the verb does not spread onto the tense suffix, which thus surfaces with its lexical M (2) tone, e.g.

$$
\begin{aligned}
& \text { lấdà dé } \quad 1.22=\text { nî ládá dé } 12.12 \text { 'I killed something' } \\
& \text { yidida toe } 1.1 .24 .4 \text {. 'I stole an axe' } \\
& \text { pleda yu } 1.221 \text { 'I bathed the child' } \\
& \text { hed } \varepsilon d a d \varepsilon \quad 1.1 .22 \quad \text { 'I counted something' }
\end{aligned}
$$

Note that with 3.2 verbs, which are assumed to have a single $r$ tone, the entire verb is raised to 1 when the floating $T$ of the first person pronoun is grounded. By contrast, only the first syllable of true ditonal verbs is raised, e.g.

$$
\begin{array}{ll}
\text { kwídèdà } & 1.3 .2=\text { ní kwidēdá } 12.3 .2 \text { 'I ran' (<kwìdē } \\
\text { pinana hne } & 1.3 .232=\text { 'I smoked fish' (< pĩna 2.3) }
\end{array}
$$


The spread of the contour tones to the suffix is accounted for by a rule such as (13), which is illustrated in (14). The stranded $M$ tone of the suffix is automatically deleted.

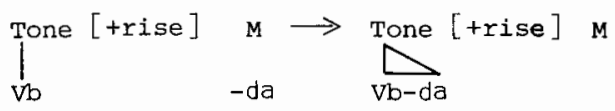

(14)
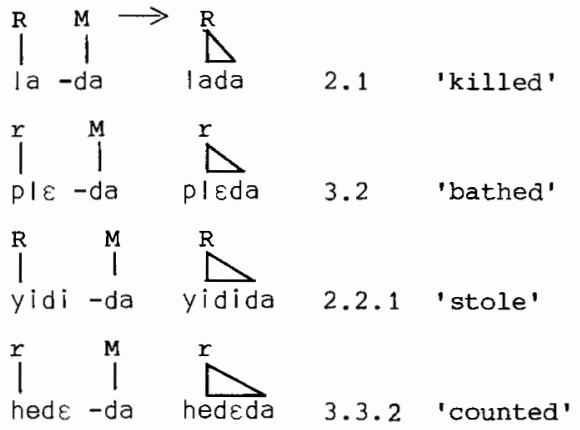

With monovocalic verbs, the surface forms could be generated as easily by an analysis in which the contours were treated as sequences--which we have rejected on other grounds--and tone was assigned on a left to right basis according to autosegmental principles (Goldsmith 1979). Such an approach would, however, provide the wrong results in the case of divocalic verbs, e.g.

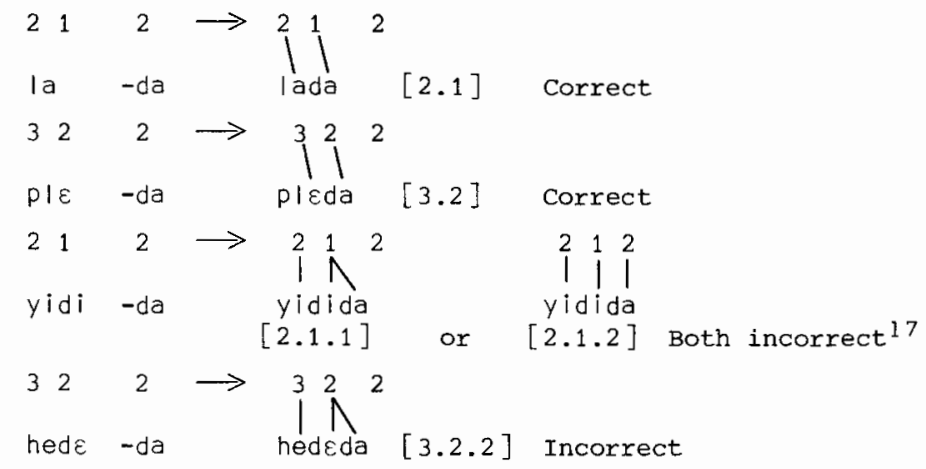

The tonal behavior of verbs with the suffix -da further supports the analysis of Grebo contours as distinct tonemes which may have as their domain one or more syllables. 


\subsection{The auxiliary negative verb yi}

In certain tenses such as the "aorist" (simple present/past), indicated by the simple verb form, and the "before yesterday past", which uses the suffix $-d a$, the negative is formed by means of an auxiliary verb yi 21 . Objects and locative goals occur after the auxiliary and before the main verb.

$$
\begin{array}{llllll}
\text { o yi Tumle yiwo } & 2 & 21 & 3.12 & 2.3 & \text { 'he doesn't know Tumle' } \\
\text { oyida maye mu } & 2 & 2.1 & 1.32 & \text { 'they didn't go to market' } \\
\text { vida bla to } & 1.24 & 32 & \text { 'I didn't buy rice' }
\end{array}
$$

When followed directly by a monovocalic main verb with underlying $M$ (2) tone, the $\mathrm{R}$ tone of the auxiliary spreads onto the verb producing a 21 sequence on the two syllables, e.g.

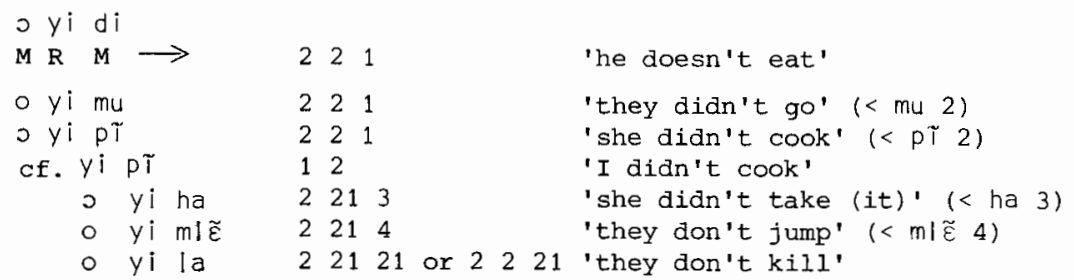

At normal speech tempos, $y i$ before a 21 verb is normally pronounced as level 2. This is due to a lower level tone simplification rule affecting $R$ and $\mathrm{R} T$ sequences that is independent of the $\mathrm{R}$ spread rule being discussed. Note that the $\mathrm{y} i \mathrm{combines}$ with the following verb to form a single tone domain only if the main verb is monovocalic. Disyllabic verbs that have contracted C1V forms thus have two different tonal manifestations, e.g.

$$
\begin{aligned}
& \text { o yi kodo } 2212.2=0 y i k l J 221 \text { 'they dian't catch (it)" } \\
& \text { o yi wẼne } 2212.2=\text { o yi wl E } 221 \text { 'it doesn't shine' }
\end{aligned}
$$

\subsection{Compounds}

As mentioned at the end of section 2, Grebo has a rule of compound lowering which assigns tone 3 to the $\mathrm{N}_{2}$ of nominal compounds, e.g. 18

$$
\begin{aligned}
& \text { bliyu 2.3 'calf' (< bli } 2 \text { 'cow' + yu } 21 \text { 'child') } \\
& \text { yons } 2.3 \text { 'palm wine' (< yo } 2 \text { 'palm' + no } 2 \text { 'wine') } \\
& \text { I umi } 21.3 .3 \text { 'airplane' (< iu 'above' + mi } 1.3 \text { 'ship') } \\
& \text { kugbo } 21.3 \text { 'bier' (< ku } 21 \text { 'deceased' + gbo 'platform') } \\
& \text { hneko } 32.3 \text { 'fish scale' (<hne } 32 \text { 'fish' + ko } 21 \text { 'shell, scale') }
\end{aligned}
$$


If the $\mathrm{N}_{1}$ has $\mathrm{R}$ tone and the $\mathrm{N}_{2}$ has $\mathrm{M}$ tone, one gets contour spreading rather than compound lowering. 19

(20) kude $2.1 \quad$ 'legacy' (<ku 21 'deceased' + de 2 'thing')

wudiblo 2.2.1 'money bag' (< wudi 2.1 'money' + blo 2 'bag')

The spreading, like the lowering, serves to indicate the bonding between the two nouns; in noun phrases, the phonological sequence 2.12 occurs naturally, e.g. biu de 2.12 'a friendly thing', sodo blo 2.12 'cassava bag'.

\subsection{Agential suffix -o}

Almost any verb in Grebo can be changed into an agential (a form corresponding to the English -er nouns) by adding a suffix $-03 / 4$. The -0 constitutes a distinct syllable and is usually separated from the preceding vowel by an epenthetic glide, $[w]$ if the verb final vowel is round, [y] otherwise. If the preceding vowel is a nasal, an epenthetic [n] is sometimes used; if it is not used, the suffixal to remains oral, e.g.

$$
\begin{aligned}
& \text { dus [du } \left.w^{\mathrm{w}} \mathrm{s}\right] \quad 2.3 \text { 'pounder' } \\
& \text { dis [di } \left.\mathrm{y}^{\mathrm{y}}\right] \quad 2.3 \text { 'eater' } \\
& \text { pĩ [pir } \\
& \text { gbas [gba } \left.{ }^{\prime}\right] \text { 4.4 'locker' }
\end{aligned}
$$

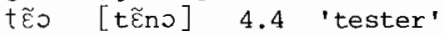

After a low tone verb the suffix has tone 4 . After a verb with $M$ tone, the suffix has tone $3, i . e$. a raised $L$. When added to verbs with contour tones, two realizations of the stem plus suffix are possible. One is to preserve the stem tone and add the suffix with stable tone 3 (which I shall indicate as $/ \mathrm{m} /$, although /L/ strictly speaking is more accurate).

(22)

$\begin{array}{llll}\text { klas } & {[21.3]} & / \text { R.m/ } & \text { 'chopper' } \\ \text { bluo } & {[21.3]} & / \text { R.m/ } & \text { 'digger' } \\ \text { tũo } & {[21.3]} & / \text { R.m/ } & \text { 'pusher' } \\ \text { pleo } & {[32.3]} & / \text { r.m/ } & \text { 'bather' } \\ \text { wว̃o } & {[32.3]} & / \text { r.m/ } & \text { 'fighter' } \\ \text { ml Ẽo } & {[32.3]} & / \text { r.m/ } & \text { 'repairer' }\end{array}$

Note that a sequential analysis of the contour tones with left to right tone assignment could not generate these surface forms unless one assumed a word boundary before the suffix, for which there is no justification. 
The other alternative is to spread the contour over the entire word including the suffix, e.g.

$\begin{array}{llll}\text { blus } & {[2.1]} & / \mathrm{R} / & \text { 'digger' } \\ \text { nas } & {[2.1]} & / \mathrm{R} / & \text { 'drinker' } \\ \text { cẽs } & {[2.1]} & / \mathrm{R} / & \text { 'learner' } \\ \text { yidis } & {[2.2 .1]} & / \mathrm{R} / & \text { 'thief' } \\ \text { sinis } & {[2.2 .1]} & / \mathrm{R} / & \text { 'sneezer' } \\ \text { ples } & {[3.2]} & / \mathrm{r} / & \text { 'bather' } \\ \text { tว̃ } & {[3.2]} & / \mathrm{r} / & \text { 'buyer' } \\ \text { jes } & {[3.2]} & / \mathrm{r} / & \text { 'farmer' } \\ \text { wudis } & {[3.3 .2]} & / \mathrm{r} / & \text { 'hider' } \\ \text { hedes } & {[3.3 .2]} & / \mathrm{r} / & \text { 'counter' }\end{array}$

With the disyllabic verbs, the contour tone spreading was required. With the monovocalic verbs the form with the stable suffix was said to be preferable, although even with the one speaker [MTW], there was considerable variation in judgements presented and in forms produced on different occasions.

\section{Discussion}

In his classic work on tone, Pike (1948) proposed that in some languages surface contours were simply sequences of level tones while in others they constituted basic tonemic units. Twenty years later, wang (1967) again argued that contour tones should be accepted as linguistic primes, a position endorsed by Fromkin (1972). Since the appearance of the important thesis by Woo (1967), the mainstream theoretical position, summarized by Anderson $(1978)^{20}$, has been against recognizing contour tones as primes. Although autosegmental phonology does not necessarily entail the rejection of contours as tonemic units (Goldsmith 1979), the "geometry" of the approach certainly favors the decomposition of contours into discrete tonal sequences and thus the theory has contributed to the general phonological attack on the integrity of the contour.

In my opinion, none of the theoretical arguments presented against contours as primes has been so compelling as to override the accumulation of descriptive and historical studies on languages of the world that show contours to exist as basic tonemic units on a par with level tones. Nor is there any reason why we should expect otherwise. As anyone familiar with vocal production knows, it is much easier to slide in and cut of a note than it is to produce a pure level pitch. Most studies that treat the phonetics of pitch 
below the phonemic level include comments on the realization of some or other level toneme as a phonetic glide; and what is phonetically cogent is bound to become phonemic in some language at some time. From a perceptual point of view it is well known that tonal glides are highly valued (Hombert 1978). This is especially so as one increases the number of tonal contrasts in a language, i.e. the more tones, the more contours (Hombert 1978). Taking only level tone binary features as primes, one would expect 4-tone systems with four distinct registers to be common among tone languages whereas they are extraordinarily rare.

With African languages there is a long tradition of treating contours as sequences. Woo (1969:99) calls this the "Africanist" approach as contrasted with the contour-receptive "Orientalist" approach. For most African languages such an analysis is probably correct, and thus one can rightly posit register tone systems as an African area typological feature. But there is a danger in translating a typological generalization into an analytical straightjacket. As Pike (1948:21) has warned, "a researcher who is familiar with register systems must hesitate lest he force contour systems into the same mold". I would argue that, theoretical and typological objections notwithstanding, the facts of Grebo show it to be a language in which contour tones constitute primary phonological units.

\section{Summary}

In this paper the following analyses were presented:

(a) Grebo has four basic tonemes: R (High Rise), M (Mid), r (low rise), and $L$ (Low) and two marginal tonemes: $T$ (Top) and $m$ (lower mid).

(b) The contour tones $\mathrm{R}$ (21) and $r$ (32) are unit tonemes and not sequences of level tones.

(c) The surface sequences (2) 2.1 and (3)3.2 found on polysyllabic words are manifestations of unit $R$ and $r$ tones spread over domains larger than a single segment.

(d) The contour tones in Grebo display an inherent predisposition to spread to the right, a characteristic that distinguishes them from the level tones. (e) Historically the Grebo $\mathrm{R}$ tone is derived from ${ }_{\mathrm{H}} \mathrm{H}$ while $r$ goes back to a low rise $\star_{r}$. Proto-Western Kru (and perhaps Proto-Kru) would seem to have had three (not four) distinct tone registers plus at least one contour toneme. 
Notes

*My research on Grebo was supported in part by a summer faculty fellowship provided by the Office of Research and Graduate Development, Indiana University I am grateful to my assistant Mlen Too wesley for his creative participation in the research.

1. All of the works by Innes listed in the References as well as the Berry and Innes (1957) article appear to be based on the same descriptive corpus and incorporate the same phonetic/phonological analysis. Unless specifically indicated otherwise, the references to Innes in the text apply to any and all of these works.

2. For two different discussions of the nasal problem in other Kru languages see Bentinck (1975) and Thalmann (1980).

3. In sentence final position, a word or tonal phrase with $\mathrm{L} L$ undergoes downdrift so that phonetically the tones sound 4.5. A similar phenomenon is found in wobe (Singler 1984).

4. As Innes points out, class B contains a couple of verbs that have tone 3 in certain limited contexts. These exceptions can be ignored for purposes of the discussion here.

5. In his thesis on Grebo tone, Luckau (1975) correctly recognized that Innes' description was very much surface level and in need of further analysis. Unfortunately he does not seem to have had the first-hand experience with the language that would have permitted him to arrive at a proper solution to the true problems of the language.

6. In referring to the contours by numerals, the phonemic units 21 and 32 should be pronounced "twenty-one" and "thirty-two" to distinguish them from sequences such as 2.3 "two, three", 4.1 "four, one", etc.

7. The term "Top" I take from welmers (1952), who, in his description of Bariba, a West African Gur language, also posits unitary contour tones as primes.

8. For most monomorphemic words transcribed by GI as 32.3, MTW had a simple $\mid r /$, i.e. 32 spread over the two syllables.

9. Compound lowering is widespread in Kru, Cf. Lightfoot (1974) for Klao, Bearth and Link (1980) for Wobe, and Gatrix (1975) for Godie.

10. In a brief paper, Elimelech (1974) interpreted the Klao rising tone as an underlying contour. This interpretation is generally taken to have been refuted by the fuller and observationally more accurate description by Iightfoot (1974). I think that the offhand rejection may have been premature. While Elimelech's paper may contain a number of errors in detail, I would suggest that his tonal analysis of Klao was basically on the right track after all.

11. Phonemically the Bassa words are all $\mathrm{H}(\mathrm{H})$. Phonetically some of the monovocalic words have rising rather than high level tone, the allotone being determined by the class of the preceding consonant.

12. In the wobe sources, high tone is indicated numerically as 2 while very high is indicated as 1 . If one adjusts the numbers so that High $=1$ (very high $=1+$ ), Mid $=2$, and Low $=4$, one finds that wobe tones directly match the corresponding tones in related languages. The wobe tone lowering presumed to have taken place historically by Bearth and Link (1980) re- 
flects nothing more than a different system of tone numeral assignment.

13. In Koyo (Kokora 1976), an eastern Kru language, a similar process of tonal glide formation has taken place, but affecting Mid not High tone. Reflecting the original level $\star_{H}$ and $\star_{M}$ tones, one finds the following correspondences between Grebo and Koyo, where one language or the other now has a contour tone: Grebo $\mathrm{R}(21)=$ Koyo $\mathrm{H}$ (1); Grebo $\mathrm{M}(2)=$ Koyo $\mathrm{R}$ (21), e.g. sว̃ 21 = so 1 'two', na $21=$ na 1 'drink', $\mathrm{kpa} 21$ = ga 1 'female'; sõ 2 = so 21 'arm', bo 2 = bo 21 'leg', tu 2 = su 21 'tree'.

14. As indicated in note 12 , the wobe tone numerals are generally one off, i.e. 43 found in the sources should really be 32 , thereby matching the Grebo 32 contour exactly. Singler (1984) provides an insightful analysis of wobe tones which should be read as a corrective and supplement to the Bearth and Link (1980) study. Although I accept much of Singler's reanalysis, I do not share his a priori objection to contour tones as such and thus I have no problem in accepting the wobe tone 43 (actually/32/) as a unit toneme.

15. According to Lightfoot (1974), there is a regular phonological rule in Klao whereby inherent low-high glides on short vowels (which she analyzes as sequences) spread onto a following word. For a general discussion of tone spreading and its relation to the notion of expandable tonal domains, see Hyman and Schuh (1974).

16. After low tone verbs, MTW allowed -da/-na with M tone, as described by Innes, but preferred a "more natural" pronunciation in which the suffix also had low tone.

17. In Mende, where, according to Leben (1978:186ff), rising contours are surface manifestations of a sequential I H pattern, trisyllabic words do appear with the expected L $\mathrm{H} \mathrm{H}$ tone.

18. MTW was much more stringent than GI in what he would accept as compounds, i.e. he treated many of GI's compounds as nominal phrases in which the $\mathrm{N}_{2}$ preserved its inherent tone. "True" compounds, however, did exhibit the appropriate tone changes.

19. Innes (1966:91) says that one also gets spreading when the $\mathrm{N}_{2}$ has 1 or 21 tone. I wasn't able to find tonally appropriate compounds that MTW would accept as true compounds in order to verify this.

20. Anderson's position strikes me as ambiguous. Since he accepts the idea of value shifts within the scope of a single segment (Anderson 1975), it is not clear why he should, or whether he actually does, totally reject the possibility of contour tones being primes in individual languages.

\section{References}

Anderson, Stephen R. (1975). The description of nasal consonants and the internal structure of segments. In: C.A. Ferguson, L.M. Hyman, and J.J. Ohala (eds.), Nasálfest, 1-25. Stanford: Department of Linguistics, Stanford University.

Anderson, Stephen R. (1978). Tone features. In: Victoria A. Fromkin (ed.), Tone: A Linguistic Survey, 133-75. New York: Academic Press.

Bearth, Thomas, and Christa link (1980). The tone puzzle of wobe. Studies in African Linguistics 11, 147-207. 
Bentinck, J. (1975). Le niaboua: langue sans consonnes nasales. Annales de I'Université d'Abidjan, Sêrie $H$, vol. 8, 5-14.

Berry, J., and G. Innes (1957). Notes on the phonetics of the Grebo language of Liberia. Mitteilungen des Instituts für Orientforschung 5, 287-98.

Duitsman, John, Jana Bertkau, and James Laesch (1975). A survey of Kru dialects. Studies in African Linquistics 6, 77-103.

Elimelech, Baruch (1974). On the reality of underlying contour tones. In: Ian Maddieson (ed.), The Tone Tome: Studies on Tone from the UCLA Tone Project, 74-83. UCLA Working Papers in Phonetics, 27.

Fromkin, Victoria A. (1972). Tone features and tone rules. Studies in African Linguistics 3, 47-76.

Gatrix, Carol (1975). Morphotonologie du godié, Annales de l'Université d'Abidjan, Série H, vol. 8, 99-114.

Goldsmith, John A. (1979). Autosegmental Phonology. New York: Garland.

Hobley, June (1964). A preliminary tonal analysis of the Bassa language. Journal of West African Languages 1.2, 51-55.

Hobley, June (n.d.). Bassa-English, English-Bassa Dictionary. Unpublished ms. In Indiana University library.

Hofer, Verena, and Christa Link (1980). Wobé. In: M.E. Kropp Dakubu (ed.), West African Language Data Sheets, Vol. 2, pp. WOB 1 - WOB 5. Leiden: West African Linguistic Society and Africa Studiecentrum.

Hombert, Jean-Marie (1978). A model of tone systems. In: Donna Jo Napoli (ed.), Elements of Tone, Stress, and Intonation, 129-43. Washington, D.C.: Georgetown University Press.

Hyman, Larry M., and Russell G. Schuh (1974). Universals of tone rules: evidence from West Africa. Linguistic Inquiry 5, 81-115.

Innes, Gordon (1960). An outline of the Grebo verbal system. African Language Studies 1, 164-76.

Innes, Gordon (1962). Morphological units in Grebo. African Language Studies 3, 84-109.

Innes, Gordon (1966). An Introduction to Grebo. London: SOAS, University of London.

Innes, Gordon (1967). A Grebo-English Dictionary. West African Language Monographs, 6. Cambridge: Cambridge University Press.

Innes, Gordon (1981). Les langues kru; Le grebo. In: Gabriel Manessy (ed.), Les langues dans le monde ancien et moderne. I. Les langues de l'Afrique subsaharienne, 125-35. Paris: CNRS.

Koelle, S.w. (1854). Polyglotta Africana. London: Church Missionary House. [Reprint with an historical introduction by P. E. H. Hair, 1963.]

Kokora, Dago Pascal (1976). Studies in the Grammar of Koyo. Ph.D. dissertation, Indiana University.

Lafage, Dhilippe (1978). Les langues kru. In: Daniel Barreteau (ed.), Inventaire des études linguistiques sur les pays d'Afrique noire d'expression française et sur Madagascar, 85-99. Paris: Conseil International de la Langue Française.

Leben, william R. (1978). The representation of tone. In: Victoria A. Fromkin (ed.), Tone: A Linguistic Survey, 177-219. New York: Academic Press.

Lightfoot, Nancy (1974). Tones on Kru monosyllables. Anthropological Linguistics $16,425-41$.

Luckau, Stephen R. (1975). A Tonal Analysis of Grebo and Jabo. Ph.D. dissertation, Stanford University.

Marchese, Lynell (1979). Atlas linguistique kru. Abidjan: Institut de linguistique appliquée, Université d'Abidjan. [3rđ revised edition 1984, not seen. ]

Pike, Kenneth L. (1948). Tone Languages. Ann Arbor: University of Michigan Press. 
Sapir, Edward (1931). Notes on the Gweabo language in Liberia. Language $7,30-41$.

Singler, John V. (1984). On the underlying representation of contour tones in wobe. Studies in African Linguistics 15, 59-75.

Thalmann, Peter (1978). Tonèmes et règles tonales du krou tépo. Annales de I'Université d'Abidjan, Série $\mathrm{H}$, vol. 11, 133-48.

Thalmann, Peter. Phonologie du kroumen. Abidjan: Institut de Linguistique Appliquée \& S.I.L.

Wang, William S.-Y. (1967). Phonological features of tone. International Journal of American Linguistics 33, 93-105.

Welmers, William E. (1952). Notes on the structure of Bariba. Language 28, 82-103.

Woo, Nancy H. (1969). Prosody and Phonology. Ph.D. dissertation, MIT. 